\section{FaRCa1 Confers Moderate Resistance to the Root Necrosis Form of Strawberry Anthracnose Caused by Colletotrichum acutatum}

\author{
Natalia Salinas and Zhen Fan \\ Horticultural Sciences Department, University of Florida, IFAS Gulf Coast \\ Research and Education Center, Wimauma, FL 33598
}

\author{
Natalia Peres \\ Department of Plant Pathology, University of Florida, IFAS Gulf Coast \\ Research and Education Center, Wimauma, FL 33598
}

\author{
Seonghee Lee and Vance M. Whitaker \\ Horticultural Sciences Department, University of Florida, IFAS Gulf Coast \\ Research and Education Center, Wimauma, FL 33598
}

Additional index words. breeding, disease resistance, Fragaria, genomics, Rosaceae

\begin{abstract}
FaRCal is a major locus conferring resistance to anthracnose fruit rot (AFR) caused by Colletotrichum acutatum, an important pathogen of strawberry (Fragaria Xananassa). The objective of this study was to characterize the effects of FaRCal on anthracnose root necrosis (ARN) via root inoculations and DNA marker characterization of the locus. A subgenome-specific high-resolution melting (HRM) marker for an insertion/deletion (InDel) near FaRCal was designed using the 'Camarosa' octoploid reference genome. The marker was used to genotype cultivars and advanced selections studied in two seasons. A root disease screening method was developed in which roots were cut and dipped in a spore suspension before planting, using a mixture of three local isolates of the $\boldsymbol{C}$. acutatum species complex. ARN was indirectly scored by calculating image-based leaf area differences among inoculated and noninoculated plants. The allele of FaR Cal conferring resistance to AFR also conferred a significant reduction in ARN. Thus, a robust and easily scored DNA test is now available to breeders for selecting for resistance to both the fruit and root forms of strawberry anthracnose.
\end{abstract}

Strawberry anthracnose caused by Colletotrichum acutatum is a disease of worldwide importance (MacKenzie and Peres, 2012; Peres et al., 2005). Up to $75 \%$ yield losses have occurred in commercial fields infected with C. acutatum (Borisova et al., 2018). Florida is the main producer of winter strawberries (Fragaria $\times$ ananassa) in the United States (Wu et al., 2012). In 2017, 20\% (4371 ha) of the total U.S. land area and 9.6\% (\$337 million) of the total U.S. production value came from Florida farms (Samtani et al., 2019). Florida strawberry farmers deal with several challenges to profitability. These include international competition, rising labor costs, and pests and diseases (Samtani et al., 2019).

C. acutatum, a fungus belonging to the Ascomycota phylum, has optimal growth between 24 and $30{ }^{\circ} \mathrm{C}$ (Smith, 1990; Wilson et al., 1990) and with continuous periods of wetness (Forcelini et al., 2016a). In Florida, $C$. acutatum does not survive the summer either on plant residue or in the soil (UreñaPadilla et al., 2001). Proliferation of $C$. acutatum in fruiting fields begins with infected transplants obtained from nurseries located in northern latitudes (Forcelini et al., 2016a). Cooler temperatures in the summer nurseries favor the quiescent stage of plant collapse (Freeman and Katan, 1997). Symptoms in roots and crown caused by $C$. acutatum are identified as ARN (Forcelini et al., 2016a). In ripening fruit, lesions are firm, dark brown, and sunken (Peres et al., 2005). Fruit disease caused by C. acutatum is known as AFR (Mertely et al., 2017).

Some strawberry organs develop more intense symptoms, regardless of the cultivar. Flowers were more susceptible and had shorter incubation periods than immature fruit for cultivars Treasure, Camarosa, and Strawberry Festival (Forcelini et al., 2016a). Different levels of resistance/susceptibility in organs of the same genotype might be the result of specific host-pathogen interactions, tissue preferences, and/or favorable climatic conditions (Forcelini et al., 2016a). Levels of resistance/susceptibility to ARN and AFR in the same strawberry cultivar or genotype have not been evaluated.

Several outbreaks of anthracnose have been reported in the past two decades, causing considerable economic impacts to farmers in Florida. To counter economic losses, different methods of disease control are applied. Exclusion of $C$. acutatum is considered the most effective control method for ARN and AFR. Strawberry transplants should be obtained from disease-free nurseries; however, strawberry transplants are typically tested only for viruses. Proper cleaning and disinfection procedures should be encouraged in personnel and equipment both in nurseries and commercial strawberry fields. AFR can be reduced considerably by fungicide applications. Chemical disease suppression, however, becomes almost impossible when lesions are present in roots and crowns. Thus, ARN often has more devastating effects than AFR in Florida. Infected transplants can be dipped in the premixture of fungicides cyprodinil+fludioxonil (Switch; Syngenta Crop Protection, Basel, Switzerland) for 5 min just before planting (Mertely et al., 2010). In Florida, the most common and effective AFR management strategy has been weekly applications of preventive and protectant fungicides, such as captan and the strobilurin fungicides azoxystrobin (Abound; Syngenta Crop Protection) and pyraclostrobin (Cabrio; BASF, Ludwigshafen, Germany) or Switch (Mertely et al., 2015, 2017). Since 2013, however, chemical control failure has been observed due to the emergence of $C$. acutatum populations resistant to strobilurin fungicides (Forcelini et al., 2016b, 2018). Consequently, genetic resistance in strawberry cultivars continues to be the preferred option to control diseases caused by C. acutatum (Gupton et al., 1995).

Previous studies have documented broad variability for resistance to AFR in University of Florida (UF) breeding germplasm, with most cultivars being moderately to highly resistant (Chandler et al., 2006; Seijo et al., 2008; Whitaker et al., 2012, 2015, 2018). Preliminary results indicate that Florida cultivars as a group have the highest overall anthracnose resistance compared with cultivars from five Californiabased strawberry breeding programs in the 
United States (Gonzalez-Benitez et al., 2019). A single locus, FaRCal, confers resistance to AFR in UF germplasm. This locus explained at least $50 \%$ of phenotypic variance for AFR incidence in two distinct quantitative trait locus (QTL) discovery populations, and was validated in advanced selections and cultivars (Salinas et al., 2019). Narrow-sense heritability $\left(h^{2}\right)$ estimates were 0.46 and 0.61 for the two populations studied. Four single-nucleotide polymorphisms (SNPs) from the Axiom IStraw35 array (Verma et al., 2017a) spanned the FaRCal region, with probe AX-89838986 having the highest explanatory value across discovery and validation populations (Salinas et al., 2019). No evidence of additional loci was found, suggesting that FaRCal alone is responsible for the resistance observed in UF germplasm and not Rca2, which confers resistance to some strains of $C$. acutatum in Europe (Denoyes-Rothan et al., 2005). The effect of FaRCal on resistance to the root form of the disease, ARN, has not been evaluated. Given the important impact of ARN in strawberry production, it is pertinent to determine the effects of FaRCal on resistance to ARN.

It also would be highly advantageous to have DNA tests for FaRCal to use in routine resistance breeding. Phenotypic selection for disease resistance requires considerable resources for trials with inoculated plants (Moose and Mumm, 2008). DNA tests for anthracnose resistance should be widely applicable due to the worldwide importance of anthracnose diseases and the frequent use of UF germplasm in breeding. In recent years, DNA testing systems combining rapid DNA extraction and high-throughput marker analysis have been implemented in strawberry research programs (Lee et al., 2016; Lee S. et al., 2017; Noh et al., 2017). Several subgenome-specific loci associated with economically important traits have been detected, and HRM markers developed that amplify only in the target subgenome whenever possible (Anciro et al., 2018; Mangandi et al., 2017; Roach et al., 2016; Salinas et al.,

Received for publication 7 Jan. 2020. Accepted for publication 2 Mar. 2020.

Published online 15 April 2020.

We acknowledge the strawberry breeding team at the Gulf Coast Research and Education Center for their assistance. We also owe a debt of gratitude to Steven J. Knapp and Pat Edger for pre-publication access to the 'Camarosa' reference genome.

Financial support for this project was provided through the Florida Strawberry Growers Association and the U.S. Department of Agriculture/National Institute of Food and Agriculture Specialty Crop Research Initiative (SCRI) project "RosBREED: Combining disease resistance with horticultural quality in new rosaceous cultivars" under Award Number 2014-51181-22378. This work was also supported by the SCRI project "NextGeneration Disease Resistance Breeding and Management Solutions for Strawberry" under Award Number 2017-51181-26833.

V.M.W. is the corresponding author. E-mail: vwhitaker@ufl.edu.

This is an open access article distributed under the CC BY-NC-ND license (https://creativecommons.org/ licenses/by-nc-nd/4.0/).
2019; Verma et al., 2017b). The unique shape of each melting curve depends on the amplicon's length, sequence, GC content, and complementarity of DNA strands (Simko, 2016; Wittwer et al., 2003). HRM markers are capable of detecting SNPs (Lee et al., 2016); however, more distinguishable curves can be produced using larger polymorphisms spanning multiple base pairs (bp). This is especially advantageous when crude DNA extracts are used in genotyping, as secondary metabolites may distort melt curves. A strawberry DNA testing handbook has been released describing 20 strawberry DNA tests (Oh et al., 2019), most of which are based on HRM.

The objectives of the present study were to 1) develop subgenome-specific HRM markers for FaRCal and confirm their utility for the fruit rot form of anthracnose (AFR) using previously published phenotypic data (Salinas et al., 2019); 2) develop a screening protocol to phenotype strawberry germplasm from UF and cultivars from other breeding programs for the root necrosis form of the disease (ARN); and 3) characterize FaRCal allele effects on ARN using the combined data from markers and phenotypes obtained in objectives 1 and 2 .

\section{Materials and Methods}

HRM marker development. Geneious R10.2 software (https://www.geneious.com) was used to 1) visualize the four chromosomes Fvb 6-1, 6-2, 6-3, and 6-4 from the octoploid 'Camarosa' genome (Edger et al., 2019); 2) align probes from the Axiom IStraw35 array to chromosomes Fvb 6-3 to explore the region around Axiom SNP probe AX-89838986 (Salinas et al., 2019), and detect subgenome-specific polymorphisms; and 3) determine if the designed primers were specific to the FaRCal region of chromosome Fvb 6-3 (Fig. 1A and B). PrimerQuest software from Integrated DNA Technologies, Inc. (www.idtdna. com/Primerquest/Home/Index) was used to design HRM primers.

Primer design parameters were customized by setting the primer temperature minimum to $58{ }^{\circ} \mathrm{C}$, optimum to $60{ }^{\circ} \mathrm{C}$, and maximum to $62{ }^{\circ} \mathrm{C}$. The amplicon size was selected to be between 50 and $80 \mathrm{bp}$. The ideal primer size was $22 \mathrm{bp}$, with an amplicon size of $50 \mathrm{bp}$. If no primers could be found within these parameters, the amplicon size was increased up to $120 \mathrm{bp}$. Five forward primers and five reverse primers (Supplemental Table 1) were tested in different combinations to assay a subgenome-specific InDel (Fig. 1B).

The $5 \mu \mathrm{L}$ polymerase chain reaction (PCR)-HRM reactions were composed of $2.5 \mu \mathrm{L} 2 \times$ AccuStart II PCR ToughMix master mix (Quantabio, Beverly, MA), 0.25 $\mu \mathrm{L} 5 \mu \mathrm{M}$ forward and reverse primer, $0.25 \mu \mathrm{L}$ $10 \times$ LCGreen Plus Melting Dye (BioFire Defense, Salt Lake City, UT), $1 \mu$ L DNA (10 $n g / \mu \mathrm{L})$, and $1 \mu \mathrm{L}$ deionized $\mathrm{H}_{2} \mathrm{O}$. The reactions were carried out in a 384-well PCR plate in a LightCycler 480 II Instrument
(Roche, Basel, Switzerland) for both PCR and HRM. Conditions of PCR were as follows: initial denaturation at $95^{\circ} \mathrm{C}$ for $30 \mathrm{~s}, 55$ cycles denaturation at $95{ }^{\circ} \mathrm{C}$ for $15 \mathrm{~s}$, annealing at $60{ }^{\circ} \mathrm{C}$ for $15 \mathrm{~s}$, and extension at $72{ }^{\circ} \mathrm{C}$ for $15 \mathrm{~s}$. After amplification, the PCR product was denatured at $95{ }^{\circ} \mathrm{C}$ for $60 \mathrm{~s}$ and cooled to $40{ }^{\circ} \mathrm{C}$ for $60 \mathrm{~s}$ to allow heteroduplex formation. The final step of HRM began at $55^{\circ} \mathrm{C}$ with $1{ }^{\circ} \mathrm{C}$ per second with 25 acquisitions per degree until $95{ }^{\circ} \mathrm{C}$. Melting curve data were collected and analyzed using the HRM software Melt Curve Genotyping and Gene Scanning available on the Roche LightCycler 480 II system. Analysis of HRM variants was based on differences in the shape of the melting curves and in Tm values.

Marker validation for AFR. A validation subset of 190 genotypes composed of four cultivars, eight advanced selections, and 178 seedlings from crosses among parents with a wide range of susceptibility and resistance to AFR was used to test the utility of an InDelbased HRM marker (Supplemental Table 2). These genotypes were inoculated in the 2016-17 season (Salinas et al., 2019). The proportion of symptomatic to total fruit harvested was determined for each plant (clonal replication) in four replications. A mean disease incidence was calculated across replications for each individual and referred to as AFR incidence (\%) (Salinas et al., 2019). Comparison of means and separation of means by the InDel-based HRM marker was performed using one-way analysis of variance (ANOVA) and the least significant difference (LSD) test in $\mathrm{R}$ software (R Core Team 2000).

ARN germplasm. In 2017-18, 11 genotypes composed of 10 cultivars and one advanced selection in the UF strawberry breeding program and representing six individuals with genotype AA and five individuals with genotype $\mathrm{AB}$ were evaluated (Supplemental Table 3). In 2018-19, 60 genotypes composed of 11 cultivars and 49 advanced selections represented 19 individuals with genotype AA, 22 with genotype $\mathrm{AB}$, and 19 with genotype $\mathrm{BB}$ were evaluated (Supplemental Table 4). Clonal replication was performed in the breeding program's summer nursery located in southern Oregon. Runner plants (clonal replicates) from each individual were allowed to root, then collected from the nursery as bare-root transplants in late September and transported to Florida for evaluation at the Gulf Coast Research and Education Center in Wimauma, FL. Thirty-two runner plants of each individual were planted in a randomized complete block design with eight plants in each of four blocks, each block consisting of two raised beds. Transplanting took place on 11 Oct. 2017 and 12 Oct. 2018.

Inoculation and ARN rating. Isolates $02-$ $163,02-179$, and $03-32$, recently described as Colletotrichum nymphaeae within the $C$. acutatum species complex (Wang et al., 2019) were used for root inoculations in 2017-18 and 2018-19 seasons. Inoculum was produced by growing these three isolates 
A

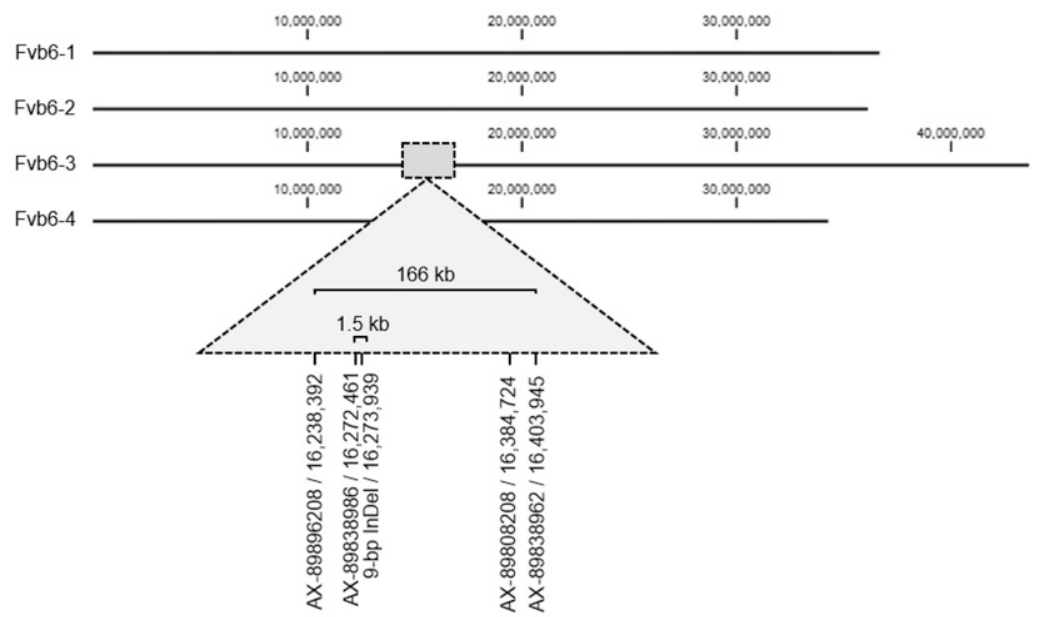

B

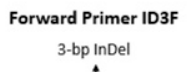

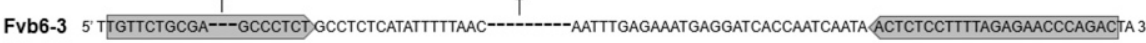
Fvb6-1 5' TTGTTCTGCGACATGCCCTCT GCCTCTCATATTTTTAACAGGTTACTTAATTTGAGAAATGATGATCACCAATCAATA ACTCTCCTTTTAGAGAACCCAGACTA 3' Fvb6-4 3' TTGITCTGCGACATGCCCTCT GCCTCTCATATTTTTAACAAGTTACTTAATTTGAGAAATGATGATCACCAATCAATA ACTCTCCTTTTAGAGAACCCAGACTA 5'

Fig. 1. (A) Location of a target region for a high-resolution melting marker linked to the FaRCaI locus on chromosome Fvb 6-3 of the octoploid 'Camarosa' reference genome. (B) Sequence of chromosome Fvb 6-3 containing a 3-bp and a 9-bp InDel aligned to the corresponding regions of chromosomes Fvb 6-1 and 6-4. Shaded regions correspond to the primers ID3F and ID1R.

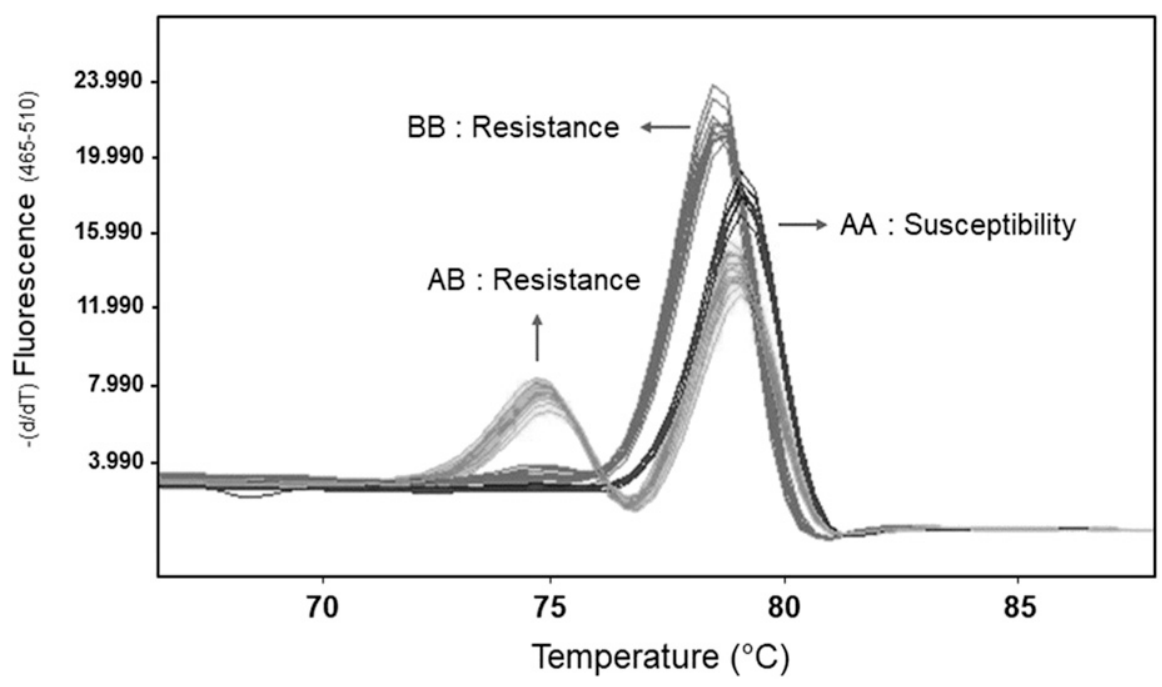

Fig. 2. Melt curves for a 9-base pair InDel-based high-resolution melting marker near the FaRCal locus and the phenotypes with which the melt curves are associated.

separately on potato dextrose agar at room temperature with constant light for $7 \mathrm{~d}$ until sporulation. Plates were flooded with steriledistilled water when growth turned orange and approached the border of the plate. A spore suspension for each isolate was passed through cheesecloth to remove dislodged mycelia. A final suspension was adjusted to $1 \times 10^{6}$ conidia/mL by combining equal concentrations of each isolate.

Roots were cut with scissors, leaving $\approx 10.16 \mathrm{~cm}$ of root from the base of the crown. The trimmed roots of each genotype were immersed in the conidia suspension (inoculated plants) or in sterilized water (noninoculated control plants) for $15 \mathrm{~s}$. In- oculated and noninoculated plants were placed in separate plastic crates, misted with sterile water, and covered with plastic bags for $12 \mathrm{~h}$ to maintain humidity and facilitate fungal penetration of the trimmed roots. Four inoculated transplants were planted adjacent to four noninoculated transplants of the same genotype in all four replications on 11 Oct. 2017 and 12 Oct. 2018. Overhead irrigation was applied after planting for $10 \mathrm{~d}$ during daylight hours to ensure plant establishment and promote the development of disease.

Root necrosis was evaluated indirectly by calculating the difference in leaf growth between noninoculated plants and inoculated plants. Pic- tures were taken $\approx 140 \mathrm{~cm}$ directly above the top of the plants using a Sony camera, model DSC-RX100M2 (Tokyo, Japan) attached to a Koolehaoda self-stick, model 288 (Shenzhen, Guangdong, China) in the morning (6:30-7:30 AM), noon, or afternoon (5:30-6:30 PM) of 21 Oct. 2017 in the first season and 25 Oct. 2018 in the second season. In each image, four noninoculated plants or inoculated plants are captured with a $10.2-\mathrm{cm}$ white line drawn on the bed top next to the plants.

Each picture was analyzed using the software ImageJ 1.52a (National Institutes of Health, Bethesda, MD) (Schneider et al., 2012). The $10.2-\mathrm{cm}$ white line was set as the global scale. New green leaves in the pictures were selected and differentiated by manually adjusting the hue, saturation and brightness in the option 'Threshold Color' in ImageJ. Total leaf area was measured for each plant based on the image analysis. Leaf area average for the four noninoculated plants $(X)$ and the four inoculated plants $(Y)$ in each replication were used to calculate the percentage of leaf area growth (LAG) difference. This was done for all genotypes in each of the four replicates according to the formula $L A G$ difference $(\%)=\left(\frac{X-Y}{X}\right) * 100$.

FaRCal effects on ARN. An InDel-based HRM marker was used to genotype the 60 individuals inoculated and rated in the 201718 and 2018-19 seasons. Comparison of means and separation of means by the InDel-based HRM marker was performed using one-way ANOVA and the LSD test in $\mathrm{R}$ software (R Core Team 2000) in both seasons. Genetic variance components were estimated by fitting the LAG difference (\%) to the linear model $y=X \beta+Z_{1} d+Z_{2} p+e$ using ASReml software (Gilmour et al., 2015), where $y$ is the vector of observations, $\beta$ is the vector of fixed effects (mean, replications), $X$ is the design matrix relating the fixed effects to the observations in $y, d$ is the vector of random beds within replicate effects, $p$ is the vector of random genotype effects, and $e$ is the vector of random residuals effects. $Z_{1}$ and $Z_{2}$ are known design matrices relating the observations in $y$ to effects in $d$ and $p$, respectively. Broad-sense heritability $\left(H^{2}\right)$ for LAG difference (\%) was estimated in both seasons with the formula $H^{2}=\frac{\sigma_{g}^{2}}{\sigma_{g}^{2}+\sigma_{b r}^{2}+\sigma_{e}^{2}}$, where $\sigma_{g}^{2}, \sigma_{b r}^{2}$, and $\sigma_{e}^{2}$ correspond to genotypic variance, bed within replicate variance, and residual variance, respectively.

\section{Results}

HRM markers. HRM markers were designed to amplify a 9-bp InDel on chromosome Fvb 6-3 of the 'Camarosa' reference genome (Fig. 1A) (Edger et al., 2019). The 9-bp InDel is located 1478 bp from the SNP assayed by the AX-89838986 probe (Fig. 1A). When testing the 10 combinations among the forward and reverse primers for this InDel specific to chromosome Fvb $6-3$, the combination with the most distinguishable melting curves was produced by 


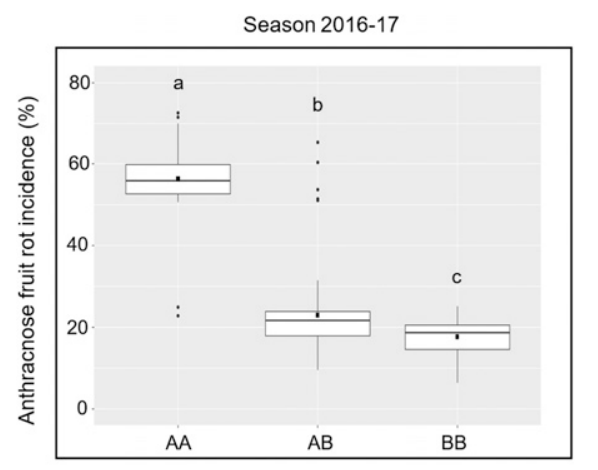

Marker genotype

Fig. 3. Boxplots showing anthracnose fruit rot incidence by marker genotype for the 9-base pair InDel-based high-resolution melting marker at the FaRCal locus for season 201617. Central horizontal lines represent medians and dark squares represent means. Dots outside the boxplots indicate outliers. Lowercase letters indicate significantly different means using the least significant difference test $(\alpha=0.05)$ in each season.

\section{A}

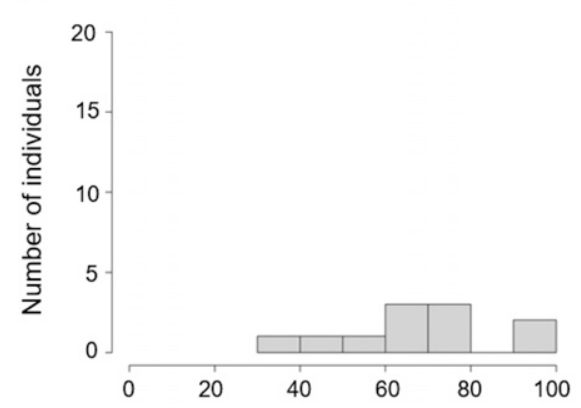

B

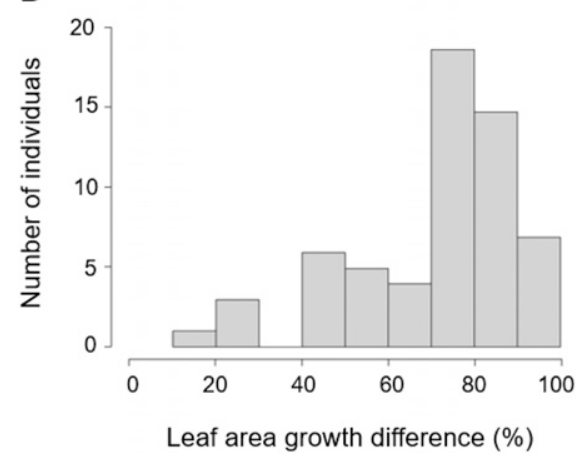

Fig. 4. Frequency distributions of the leaf area growth difference (\%) between plants with roots inoculated with Colletotrichum acutatum and noninoculated plants for (A) season $2017-$ 18; and (B) season 2018-19.

primer ID3F and ID1R (Figs. 1B and 2, Supplemental Table 1).

Marker validation for AFR. A validation subset composed of 190 individuals was previously scored for AFR incidence in 2016-17 (Salinas et al., 2019). These individuals showed a wide range of disease incidence (Supplemental Table 2). For the InDel-based HRM test using markers ID3F and ID1R, there were 54 individuals with genotype AA, 84 individuals with genotype $\mathrm{AB}$, and 52 individuals with genotype $\mathrm{BB}$. The mean AFR incidences for individuals with genotypes $\mathrm{AA}, \mathrm{AB}$, and $\mathrm{BB}$ were $56.3 \%$, $23.0 \%$, and $17.7 \%$, respectively. One-way ANOVA indicated a significant effect of marker genotype on AFR incidence $[\operatorname{Pr}(>F)$ $\left.=2.2 \mathrm{e}-16^{* * *}\right]$. Separation of means using the LSD test showed three significantly different groups by marker genotype (Fig. 3).

ARN phenotypes. A wide range of $\mathrm{LAG}$ difference means (\%) as determined with image analysis was observed in both seasons. LAG difference means ranged from $36.4 \%$ to $96.1 \%$ and from $21.8 \%$ to $100 \%$ in the 2017 18 and 2018-19 seasons, respectively (Fig. 4). Frequency distributions were skewed toward lower values (resistance) in both populations. LAG difference means (\%) for individuals analyzed in both seasons are shown in Supplemental Tables 3 and 4.

FaRCal effects on ARN. In 2017-18, among the 11 individuals tested, there were six AA (homozygous susceptible) and five $\mathrm{AB}$ (heterozygous resistant) genotypes according to the 9-bp InDel-based HRM marker. LAG difference means corresponding to genotypes $\mathrm{AA}$ and $\mathrm{AB}$ were $75.5 \%$ and $56.9 \%$, respectively. Comparison of means and separation of means showed no significant differences between marker genotypes $[\operatorname{Pr}(>F)=0.11]$ (Fig. 5A). In 2018-19, among the 60 individuals tested, there were 20 AA (homozygous susceptible), $22 \mathrm{AB}$ (heterozygous resistant), and 18 BB (homozygous resistant) genotypes for the 9-bp InDel-based HRM marker. LAG differences corresponding to genotypes $\mathrm{AA}, \mathrm{AB}$, and $\mathrm{BB}$ were $83.6 \%, 67.1 \%$, and $61.1 \%$, respectively. Comparison of LAG differences means (\%) using the one-way ANOVA test indicated significant differences among groups by marker genotypes $[\operatorname{Pr}(>\mathrm{F})=3.3 \mathrm{e}-14 * * *]$. Separation of means indicated two significantly different groups, one corresponding to genotype AA (susceptibility) and the other corresponding to genotypes $\mathrm{AB}$ and $\mathrm{BB}$ (resistance) (Fig. 5B). Estimates of $H^{2}$ for ARN were 0.60 and 0.36 for the 2017-18 and 2018-19 seasons, respectively.

\section{Discussion}

C. acutatum, an economically important pathogen worldwide and one of the most devastating pathogens of strawberry in Florida, can cause up to $75 \%$ of yield losses in commercial production (Borisova et al., 2018). Genetic resistance is the most preferable control method for managing this pathogen in a sustainable manner. Previously, FaRCal was discovered and determined to confer high levels of resistance to the fruit form of anthracnose; however, it was unknown how effective the locus FaRCal was against the root form of the disease. Specific interactions between different organs of strawberry and the pathogen can result in various levels of anthracnose disease in the same plant (Forcelini et al., 2016a), and FaRCal effects on ARN have not been pre- viously documented. ARN is particularly important because once root disease is found in newly planted fields, control methods are severely limited. In this study, we report the effects of FaRCal, initially associated with AFR resistance, on ARN using a newly developed HRM marker suitable for highthroughput breeding applications.

In octoploid strawberry, codominant HRM assays that can be reliably scored when using crude DNA extracts are usually possible only with subgenome-specific amplification. High quantities of secondary metabolites, such as polysaccharides and polyphenols, are present in strawberry leaves (Fang et al., 1992; Nunes et al., 2011), and it is very common to observe their negative effects on HRM assays using crude extracts. A subgenome-specific InDel was found 1478 bases from the SNP interrogated by Axiom probe AX-89838986 (Thermo Fisher, Santa Clara, CA) on chromosome Fvb 6-3 (Fig. 1A). Primers ID3F and ID1R target this 9-bp InDel (Fig. 1B) and produce distinguishable melting curves that were identical in pure and crude DNA extracts (Fig. 2). In addition, primer ID3F spans a 3-bp InDel specific to chromosome Fvb 6-3 and adjacent to the 9-bp InDel, giving subgenome-specific amplification of the PCR product (Figs. 1B and 2). Using these two InDels, one for primer specificity to the Fvb 6-3 subgenome and the other as the target polymorphism for the assay, produced a robust DNA test (Fig. 2)

A population of 190 individuals was scored for AFR incidence in the 2016-17 season (Salinas et al., 2019) and then genotyped with the newly developed marker using primers ID3F and ID1R (Supplemental Table 2). Three statistically different groups corresponding to genotypes $\mathrm{AA}, \mathrm{AB}$, and $\mathrm{BB}$ were distinguished, reflecting the major effect of FaRCal on controlling AFR resistance (Fig. 3). Thus, this HRM assay should prove valuable to the UF breeding program and other programs breeding for FaRCalmediated anthracnose resistance. A Strawberry DNA Testing Handbook was recently developed that reports 10 DNA tests suitable for disease resistance traits in strawberry (Oh et al., 2019). The InDel-based HRM test for FaRCal will form a useful addition to this resource.

During two consecutive seasons, two populations were root inoculated and scored for ARN using image analysis. Eleven and 60 individuals were screened in 2017-18 and 2018-19, respectively. Because the root inoculation and scoring technique by image analysis was being developed for this study, a smaller population was used in the first year. Leaf area image analysis was used to indirectly score ARN in individuals analyzed in this study. Surprisingly, within 2 weeks of inoculation, many susceptible individuals had leaf areas of only a fraction of the noninoculated controls, illustrating the severe effects of the root necrosis form of the disease on the aboveground portions of the plants. Subjective scales, such as 0 to 6 ratings, have been previously used to score 


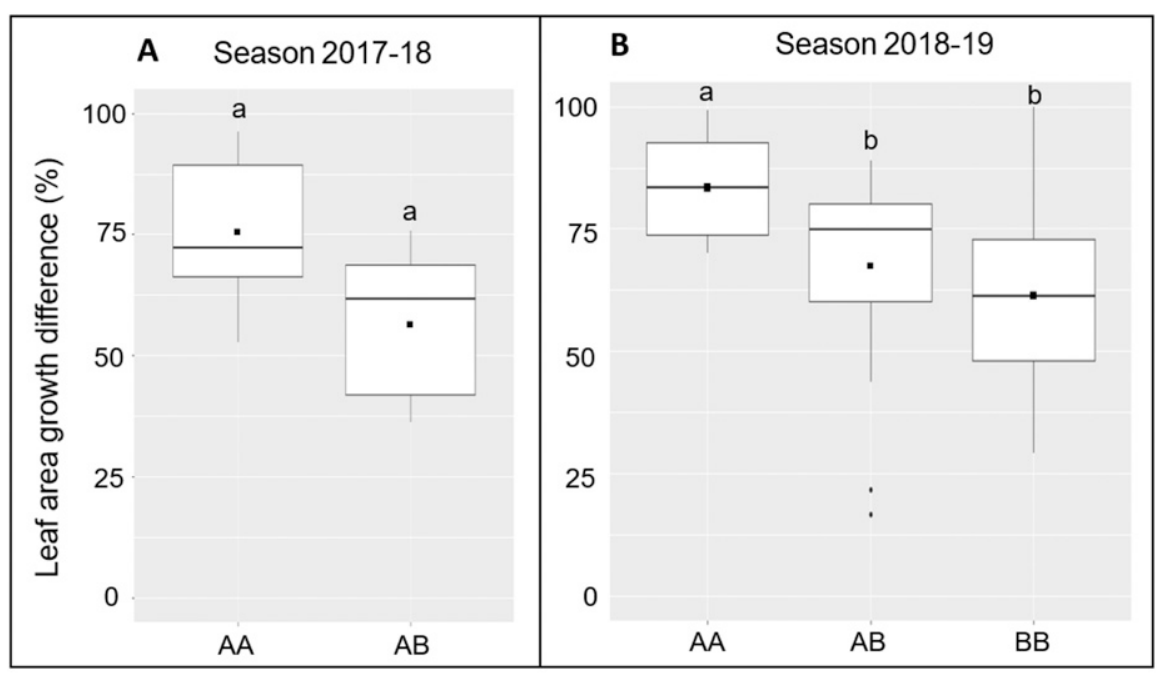

Marker genotype

Fig. 5. Boxplots showing leaf area growth difference after root inoculation by marker genotype for the 9base pair InDel-based high-resolution melting marker at the FaRCal locus for season (A) 2017-18 and (B) 2018-19. Central horizontal lines represent medians and dark squares represent means. Dots outside the boxplots indicate outliers. Lowercase letters indicate significantly different means using the least significant difference test $(\alpha=0.05)$ in each season.

symptoms caused by C. acutatum (DenoyesRothan et al., 2004, 2005; Gupton et al., 1995; Lewers et al., 2007). Repeatability, accuracy, and precision of visual rating scales to score disease symptoms is rater dependent (Poland and Nelson, 2011). Image analysis can produce more accurate measurements, allowing higher resolution and greater power to differentiate phenotypes. In a previous example, image analysis was used to measure common bacterial blight lesions caused by Xanthomonas campestris pv. phaseoli and Xanthomonas fuscans subsp. fuscans on bean (Phaseolus vulgaris) leaves. Results showed that image analysis was more sensitive than visual assessments in detecting quantitative differences between bean genotypes and that visual assessments overestimated QTL effects in genetic studies (Xie et al., 2012).

In strawberry, image analysis has been used mainly for assessment of diseases such as powdery mildew and conditions such as fruit shrinkage and uneven ripening (Ouyang et al., 2013). Image analysis has been also performed to examine important strawberry fruit traits, such as volume (Lee D.H. et al., 2017), shape (Ishikawa et al., 2018), and maturity (Raut and Bora, 2016), as well as calyx size, achene number, and color ( $\mathrm{He}$ et al., 2017). To our knowledge, highthroughput image analysis has not yet been implemented to routinely score phenotypes in strawberry breeding programs. For future experiments, we recommend using a camera attached to a stable rolling cart, facilitating movement between beds and steadiness of the camera. In addition, using a red square instead of a white line as a standard object might facilitate automation, as demonstrated in the plant model Arabidopsis via Easy Leaf Area software (Easlon and Bloom, 2014).

In 2017-18, the LAG difference between homozygous susceptible (AA) and heterozygous
(AB) groups was not significant at the $P<0.05$ level because of the small sample size in the initial experiment (Fig. 5A); however, the larger values of LAG differences corresponded to the susceptible genotype (AA). The same trend was observed the following year. In 2018-19, the 9-bp InDel-based HRM marker was able to distinguish ARN-susceptible individuals (AA) from ARNresistant individuals ( $\mathrm{AB}$ and $\mathrm{BB}$ ) (Fig. 5B). The near-complete dominant gene action of $\mathrm{FaRCal}$ observed for AFR is less apparent for ARN (Figs. 3 and 5). FaRCal confers a stronger effect on AFR resistance than on ARN resistance, which is expected based on a higher level of genetic control for AFR than for ARN.

FaRCal confers high levels and moderate levels of resistance to AFR and ARN, respectively. Factors such as inoculation method, phenotyping method, inherent interactions of pathogen and plant organ, and the germplasm analyzed are relevant to interpreting the results in this study. Trimming roots before inoculation and the resulting stress created in resistant plants may have resulted in a lowered defense response to the pathogen. In Pincot et al. (2018), a high broad-sense heritability $\left(H^{2}=\right.$ 0.96 ) was obtained after infecting strawberry roots that were not trimmed with Fusarium oxysporum f. sp. fragariae inoculum. Also, the 9-bp InDel-based marker in FaRCal is located at an unknown distance from the causal gene controlling resistance to $C$. acutatum. Observed outliers might be the result of recombination events between the InDel-based marker and the still unknown causal gene (Figs. 3 and 5). Some other traits rated via root and crown inoculation in UF germplasm have had low-to-moderate heritability (Mangandi et al., 2017). It may be that differences in root growth rate and overall plant vigor among genotypes may be confounded with disease responses when phenotyping root and crown diseases in this manner.
Selection with the InDel-based HRM marker developed in this study should simultaneously result in lower incidence of both AFR and ARN in breeding populations segregating for FaRCal. However, the presence of the resistant allele of FaRCal does not completely suppress AFR or ARN (Figs. 3 and 5). Many homozygous resistant individuals (BB) had LAG difference values greater than $50 \%$, which still translate to significant economic impacts in commercial fields. We recommend an integrated system in which cultural and chemical disease controls in nurseries and commercial fields are practiced together with the use of resistant cultivars.

Future work is needed to identify the gene or genes controlling the resistance to develop functional markers, as well as for other potential applications, such as gene editing. The 'Camarosa' genome assembly will be further used as a map reference for characterizing genes in the FaRCal region by comparing resequencing data from resistant and susceptible individuals. Combining resequencing data with $\mathrm{R}$ gene sequence capture and gene expression analysis should lead to discovery of candidate $\mathrm{R}$ genes in the FaRCal region.

\section{Literature Cited}

Anciro, A., J. Mangandi, S. Verma, N. Peres, V.M. Whitaker, and S. Lee. 2018. FaRCg1: A quantitative trait locus conferring resistance to Colletotrichum crown rot caused by Colletotrichum gloeosporioides in octoploid strawberry. Theor. Appl. Genet. 131:2167-2177.

Borisova, T., Z. Guan, E. Vorotnikova, N.A. Peres, and J. VanSickle. 2018. Florida strawberry producer's experiences with anthracnose and botrytis fruit rot, and producers' use of the strawberry advisory system. 10 Oct. 2019. <https://edis.ifas. ufl.edu/pdffiles/FE/FE95700.pdf $>$.

Chandler, C.K., J.C. Mertely, and N. Peres. 2006. Resistance of selected strawberry cultivars to Anthracnose Fruit Rot and Botrytis Fruit Rot. Acta Hort. 708:123-126.

Debode, J., W.V. Hemelrijck, X.M. Xu, M. Maes, P. Creemers, and K. Heungens. 2015. Latent entry and spread of Colletotrichum acutatum (species complex) in strawberry field. Plant Pathol. 64:385-395.

Denoyes-Rothan, B., G. Guérin, E. LerceteauKöhler, and G. Risser. 2005. Inheritance of resistance to Colletotrichum acutatum in Fragaria $\times$ ananassa. Phytopathology 95:405-412.

Denoyes-Rothan, B., E. Lerceteau-Köhler, G Guérin, S. Bosseur, J. Bariac, E. Martin, and P. Roudeillac. 2004. QTL analysis for resistances to Colletotrichum acutatum and Phytophthora cactorum in octoploid strawberry (Fragaria Xananassa). Acta Hort. 663:147-152.

Easlon, H.M. and A.J. Bloom. 2014. Easy Leaf Area: Automated digital image analysis for rapid and accurate measurement of leaf area. Appl. Plant Sci. 2:1400033.

Edger, P.P., T.J. Poorten, R. VanBuren, M.A. Hardigan, M. Colle, M.R. McKain, R.D. Smith, S.J. Teresi, A.D.L. Nelson, C.M. Wai, E.I. Alger, K.A. Bird, A.E. Yocca, N. Pumplin, S. Ou, G. Ben-Zvi, A. Brodt, K. Baruch, T. Swale, L. Shiue, C.B. Acharya, G.S. Cole, J.P. Mower, K.L. Childs, N. Jiang, E. Lyons, M. Freeling, J.R. Puzey, and S.J. Knapp. 2019. Origin and evolution of the octoploid strawberry genome. Nat. Genet. 51:541-547.

Fang, G., S. Hammar, and R. Grumet. 1992. A quick and inexpensive method for removing 
polysaccharides from plant genomic DNA. Biotechniques 13:52-54, 56.

Forcelini, B.B., F.P. Gonçalves, and N.A. Peres. 2016a. Effect of inoculum concentration and interrupted wetness duration on the development of anthracnose fruit rot of strawberry. Plant Dis. 101:372-377.

Forcelini, B.B., C.S. Rebello, N.Y. Wang, and N. Peres. 2018. Fitness, competitive ability and mutation stability of isolates of Colletotrichum acutatum from strawberry resistant to QoI fungicides. Phytopathology 108:462-468.

Forcelini, B.B., T.E. Seijo, A. Amiri, and N.A. Peres. 2016b. Resistance in strawberry isolates of Colletotrichum acutatum from Florida to quinone-outside inhibitor fungicides. Plant Dis. 100:2050-2056.

Freeman, S. and T. Katan. 1997. Identification of Colletotrichum species responsible for anthracnose and root necrosis of strawberry in Israel. Phytopathology 87:516-521.

Gilmour, A.R., B.J. Gogel, B.R. Cullis, S.J. Welham, and R. Thompson. 2015. ASReml User Guide Release 4.1 Functional Specification. VSN International Ltd, Hemel Hempstead, UK. $<$ www.vsni.co.uk>.

Gonzalez-Benitez, O., M. Mansouripour, K. Blauer, and G. Holmes. 2019. Evaluation of host resistance to anthracnose in strawberry-2019. 30 Nov. 2019. $<$ https://content-calpoly-edu.s3.under_amazonaws. com/strawberry/1/images/8_Anthracnose $\% 20-\%$ 20Gonzalez.pdf $>$.

Gupton, C.L., B.J. Smith, and G.J. Galleta. 1995. Breeding small fruit for disease resistance in a humid climate. Acta Hort. 403:131-139.

He, J.Q., R.J. Harrison, and B. Li. 2017. A novel 3D imaging system for strawberry phenotyping. Plant Methods 13:93.

Ishikawa, T., A. Hayashi, S. Nagamatsu, Y. Kyutoku, I. Dan, T. Wada, K. Oku, Y. Saeki, T. Uto, T. Tanabata, S. Isobe, and N. Kochi. 2018. Classification of strawberry fruit shape by machine learning. Intl. Arch. Photogramm. Remote Sens. Spat. Inf. Sci XLII-2:463-470.

Lee, D.H., Y. Cho, and J.M. Choi. 2017. Strawberry volume estimation using smartphone image processing. Hort. Sci. Technol. 35:707-716.

Lee, S., Y.H. Noh, J.A. Roach, J. Mangandi, S. Verma, V.M. Whitaker, and K.R. Cearley. 2017. A high-throughput genotyping system combining rapid DNA extraction and highresolution melting analysis in allo-octoploid strawberry. Acta Hort. 1156:89-94.

Lee, S., Y.H. Noh, S. Verma, and V.M. Whitaker. 2016. DNA, technology, and Florida strawberries. Horticultural Sciences Department, UF/IFAS Extension, Series HS1287. 8 Oct. 2019. <https:// edis.ifas.ufl.edu/pdffiles/HS/HS128700.pdf>.

Lewers, K.S., W.W. Turechek, S.C. Hokanson, J.L. Maas, J.F. Hancock, S. Serce, and B.J. Smith. 2007. Evaluation of elite native strawberry germplasm for resistance to anthracnose crown rot disease caused by Colletotrichum species. J. Amer. Soc. Hort. Sci. 132:842-849.

MacKenzie, S.J. and N.A. Peres. 2012. Use of leaf wetness and temperature to time fungicide applications to control anthracnose fruit rot of strawberry in Florida. Plant Dis. 96: 522-528.

Mangandi, J., S. Verma, L. Osorio, N.A. Peres, E. van de Weg, and V.M. Whitaker. 2017. Pedigree-based analysis in a multiparental population of octoploid strawberry reveals QTL alleles conferring resistance to Phytophthora cactorum. G3 (Bethesda) 7:1707-1719.

Mertely, J.C., B.B. Forcelini, and N.A. Peres. 2017. Anthracnose fruit rot of strawberry. University of Florida, IFAS, EDIS, PP-207. 25 Sept. 2019. $<$ https://edis.ifas.ufl.edu/pdffiles/PP/PP13000.pdf $>$.

Mertely, J.C., T.E. Seijo, and N.A. Peres. 2010. Effect of pre- and post-plant fungicide and fertilizer treatments on infection by Colletotrichum acutatum, plant survival, and yield of annual strawberry in Florida. Plant Health Prog. 11:30.

Mertely, J.C., T.E. Seijo, and N.A. Peres. 2015. Evaluation of products for anthracnose and Botrytis fruit rot control in annual strawberry, 2014-2015. Plant Disease Management Reports 9:SMF019. 1 Nov. 2019. <https://www.plantmanagementnetwork.org/ pub/trial/PDMR/reports/2015/SMF019.pdf>.

Moose, S.P. and R.H. Mumm. 2008. Molecular plant breeding as the foundation for 21st century crop improvement. Plant Physiol. 147:969-977.

Noh, Y.H., S. Lee, V.M. Whitaker, K.R. Cearley, and J.S. Chaa. 2017. A high-throughput markerassisted selection system combining rapid DNA extraction high-resolution melting and simple sequence repeat analysis: Strawberry as a model for fruit crops. J. Berry Res. 7:23-31.

Nunes, C.F., J.L. Ferreira, M.C.N. Fernandes, S.D. Breves, A.L. Generoso, B.D.F. Soares, M.S.C. Dias, M. Pasqual, A. Borem, and G.M.D. Cancado. 2011. An improved method for genomic DNA extraction from strawberry leaves. Cienc. Rural 41:1383-1389.

Oh, Y., J.D. Zurn, N. Bassil, P.P. Edger, S.J. Knapp, V.M. Whitaker, and S. Lee. 2019. The strawberry DNA testing handbook. HortScience 54:2267-2270.

Ouyang, C., D. Li, J. Wang, S. Wang, and Y. Han. 2013. The research of the strawberry disease identification based on image processing and pattern recognition. Computer and Computing Technologies in Agriculture VI. CCTA 2012. IFIP Adv. Inf. Commun. Technol. 392:69-77.

Peres, N.A., L.W. Timmer, J.E. Adaskaveg, and J.C. Correll. 2005. Lifestyles of Colletotrichum acutatum. Plant Dis. 89:784-796.

Pincot, D.D.A., T.J. Poorten, M.A. Hardigan, J.M. Harshman, C.B. Acharya, G.S. Cole, T.R. Gordon, M. Stueven, P.P. Edger, and S.J. Knapp. 2018. Genome-wide association mapping uncovers $F w 1$, a dominant gene conferring resistance to fusarium wilt in strawberry. G3 (Bethesda) 8:1817-1828.

Poland, J.A. and R.J. Nelson. 2011. In the eye of the beholder: The effect of rater variability and different rating scales on QTL mapping. Phytopathology 101:290-298.

Raut, K. and V. Bora. 2016. Assessment of fruit maturity using digital image processing. Intl. J. Sci. Technol. Eng. 3:273-279.

Roach, J.A., S. Verma, N.A. Peres, A.R. Jamieson, W.E. van de Weg, M.C. Bink, N.V. Bassil, S. Lee, and V.M. Whitaker. 2016. FaRXf1: A locus conferring resistance to angular leaf spot caused by Xanthomonas fragariae in octoploid strawberry. Theor. Appl. Genet. 129:1191-1201.

Salinas, N., S. Verma, N. Peres, and V.M. Whitaker. 2019. FaRCa1: A major subgenome-specific locus conferring resistance to Colletotrichum acutatum in strawberry. Theor. Appl. Genet. 132:1109-1120.

Samtani, J.B., C.R. Rom, H. Friedrich, S.A. Fennimore, C.E. Finn, A. Petran, R.W. Wallace, M.P. Pritts, G. Fernandez, C.A. Chase, C. Kubota, and B.
Bergefurd. 2019. The status and future of the strawberry industry in the United States. HortTechnology 29:11-24.

Schneider, C.A., W.S. Rasband, and K.W. Eliceiri. 2012. NIH Image to ImageJ: 25 years of image analysis. Nat. Methods 9:671-675.

Seijo, T.E., C. Chandler, J.C. Mertely, C. Moyer, and N.A. Peres. 2008. Resistance of strawberry cultivars and advanced selections to anthracnose and Botrytis fruit rots. Proc. Annu. Meet. Fla. State Hort. Soc. 121:246-248.

Simko, I. 2016. High-resolution DNA melting analysis in plant research. Trends Plant Sci. 21:528-537.

Smith, B.J. 1990. Morphological, cultural, and pathogenic variation among Colletotrichum species isolated from strawberry. Plant Dis. 74:69-76.

Stapleton, S.C., C.K. Chandler, J.F. Price, D.E. Legard, and J.C. Sumler. 2001. Transplant source affects fruiting performance and pests of 'Sweet Charlie' strawberry in Florida. HortTechnology 11:61-65.

Ureña-Padilla, A.R., D.J. Mitchell, and D.E. Legard. 2001. Oversummer survival of inoculum for Colletotrichum Crown Rot in buried strawberry crown tissue. Plant Dis. 85:750-754.

Verma, S., N.V. Bassil, E. van de Weg, R.J. Harrison, A. Monfort, J.M. Hidalgo, I. Amaya, B. Denoyes, L. Mahoney, T.M. Davis, Z. Fan, S. Knapp, and V.M. Whitaker. 2017a. Development and evaluation of the Axiom ${ }^{\circledR}$ IStraw35 384HT array for the allo-octoploid cultivated strawberry Fragaria ×ananassa. Acta Hort. 1156:75-82.

Verma, S., J.D. Zurn, N. Salinas, M.M. Mathey, B. Denoyes, J.F. Hancock, C.E. Finn, N.V. Bassil, and V.M. Whitaker. 2017b. Clarifying subgenomic positions of QTLs for flowering habit and fruit quality in U.S. strawberry (Fragaria $\mathrm{x}$ ananassa) breeding populations using pedigreebased QTL analysis. Hort. Res. 4:17062.

Wang, N.Y., B.B. Forcelini, and N. Peres. 2019. Anthracnose fruit and root necrosis of strawberry are caused by a dominant species within the Colletotrichum acutatum species complex in the United States. Phytopathology 109:1293-1301.

Whitaker, V.M., C.K. Chandler, and N.A. Peres. 2015. Sensation ${ }^{\mathrm{TM}}$ 'Florida127' strawberry. HortScience 50:1088-1091.

Whitaker, V.M., C.K. Chandler, B.M. Santos, and N. Peres. 2012. Winterstar'TM ('FL 05-107') Strawberry. HortScience 47:296-298.

Whitaker, V.M., N.A. Peres, and S. Agehara. 2018. 'Florida Brilliance' Strawberry. University of Florida, IFAS, EDIS, HS1322. 9 Nov. 2019. < https:// edis.ifas.ufl.edu/pdffiles/HS/HS132200.pdf>.

Wilson, L.L., L.V. Madden, and M.A. Ellis. 1990. Influence of temperature and wetness duration on infection of immature and mature strawberry fruit by Colletotrichum acutatum. Amer. Phytopathol. Soc. 80:111-116.

Wittwer, C.T., G.H. Reed, C.N. Gundry, J.G. Vandersteen, and R.J. Pryor. 2003. Highresolution genotyping by amplicon melting analysis using LCGreen. Clin. Chem. 49:853-860.

Wu, F., Z. Guan, and A. Whidden. 2012. Strawberry industry overview and outlook. University of Florida, Institute of Food and Agricultural Sciences, University of Florida. 16 Oct. 2019. < https:// fred.ifas.ufl.edu/pdf/webinar/Strawberry.pdf $>$.

Xie, W., K. Yu, K.P. Pauls, and A. Navabi. 2012. Application of image analysis in studies of quantitative disease resistance, exemplified using common bacterial blight-common bean pathosystem. Phytopathology 102:434-442. 
Supplemental Table 1. High-resolution melting primers flanking a 9-bp InDel near the FaRCal locus. Primers chosen for the final assays are in bold.

\begin{tabular}{ll}
\hline & Forward primers \\
\hline ID1F & \\
ID2F & $5^{\prime}$-CTT GTC TAT GGC CAC CGC-3' \\
ID3F & $5^{\prime}$-ACC GCC ACT GCC TGT T-3' \\
ID4F & $\mathbf{5}^{\prime}$-TGT TCT GCG AGC CCT CT-3' \\
ID5F & $5^{\prime}$-CCC TCT GCC TCT CAT ATT-3' \\
ID1R & $5^{\prime}$ '-CAA ATG TTG TTC TGC GAG C-3' \\
ID2R & \\
ID3R & Reverse primers \\
ID4R & \\
ID5R & $\mathbf{5}^{\prime}$-GTC TGG GTT CTC TAA AAG GAG AGT-3' \\
\hline
\end{tabular}


Supplemental Table 2. Genotypes from Axiom IStraw35 single-nucleotide polymorphism probe AX-89838986 and a 9-base pair insertion/deletion (InDel) assayed via high-resolution melting, and 2016-17 anthracnose fruit rot (AFR) incidence mean for four strawberry cultivars and 186 selections. AFR Incidence Mean (\%) was previously obtained from Salinas et al. (2019).

\begin{tabular}{|c|c|c|c|}
\hline Individual & AX-89838986 & InDel & AFR incidence mean (\%) \\
\hline $16.54-64$ & $\mathrm{AA}$ & $\mathrm{AA}$ & 22.78 \\
\hline $16.28-35$ & AA & $\mathrm{AA}$ & 24.90 \\
\hline $16.59-60$ & AA & $\mathrm{AA}$ & 50.53 \\
\hline $16.25-42$ & $\mathrm{AA}$ & AA & 51.23 \\
\hline $16.36-22$ & AA & $\mathrm{AA}$ & 51.38 \\
\hline $16.27-11$ & AA & AA & 51.40 \\
\hline $16.54-83$ & $\mathrm{AA}$ & AA & 51.58 \\
\hline $16.81-123$ & $\mathrm{AA}$ & AA & 51.78 \\
\hline $16.54-62$ & $\mathrm{AA}$ & AA & 52.00 \\
\hline $16.40-94$ & AA & AA & 52.20 \\
\hline $16.56-30$ & $\mathrm{AA}$ & AA & 52.30 \\
\hline $16.81-112$ & AA & AA & 52.30 \\
\hline $16.50-8$ & $\mathrm{AA}$ & AA & 52.58 \\
\hline $16.73-61$ & AA & $\mathrm{AA}$ & 52.63 \\
\hline $16.81-36$ & AA & AA & 52.88 \\
\hline $16.77-80$ & AA & AA & 52.93 \\
\hline $16.54-21$ & $\mathrm{AA}$ & AA & 53.00 \\
\hline $13.55-195$ & $\mathrm{AA}$ & AA & 53.48 \\
\hline $16.74-20$ & $\mathrm{AA}$ & AA & 53.80 \\
\hline $16.77-75$ & $\mathrm{AA}$ & AA & 53.93 \\
\hline $16.60-144$ & $\mathrm{AA}$ & $\mathrm{AA}$ & 54.08 \\
\hline $16.54-75$ & $\mathrm{AA}$ & AA & 54.23 \\
\hline $16.69-70$ & $\mathrm{AA}$ & AA & 54.43 \\
\hline $16.56-86$ & $\mathrm{AA}$ & AA & 54.63 \\
\hline $16.54-18$ & $\mathrm{AA}$ & AA & 54.78 \\
\hline $16.60-73$ & $\mathrm{AA}$ & AA & 55.10 \\
\hline $16.56-27$ & $\mathrm{AA}$ & AA & 55.18 \\
\hline $16.69-17$ & $\mathrm{AA}$ & AA & 56.55 \\
\hline $16.41-55$ & AA & AA & 57.00 \\
\hline $16.9-81$ & $\mathrm{AA}$ & $\mathrm{AA}$ & 57.20 \\
\hline $16.71-32$ & $\mathrm{AA}$ & $\mathrm{AA}$ & 57.25 \\
\hline $16.74-11$ & $\mathrm{AA}$ & AA & 57.60 \\
\hline $16.56-83$ & $\mathrm{AA}$ & $\mathrm{AA}$ & 57.97 \\
\hline $16.41-2$ & $\mathrm{AA}$ & AA & 58.03 \\
\hline $16.69-118$ & $\mathrm{AA}$ & AA & 58.03 \\
\hline $16.52-34$ & AA & AA & 58.10 \\
\hline $16.41-52$ & $\mathrm{AA}$ & AA & 58.73 \\
\hline $16.74-15$ & $\mathrm{AA}$ & $\mathrm{AA}$ & 58.80 \\
\hline $16.54-5$ & $\mathrm{AA}$ & $\mathrm{AA}$ & 59.87 \\
\hline $16.52-88$ & AA & AA & 59.88 \\
\hline $16.69-4$ & $\mathrm{AA}$ & $\mathrm{AA}$ & 60.03 \\
\hline $16.25-49$ & $\mathrm{AA}$ & AA & 60.53 \\
\hline $16.52-85$ & $\mathrm{AA}$ & AA & 61.30 \\
\hline $16.56-13$ & $\mathrm{AA}$ & AA & 61.70 \\
\hline $16.25-73$ & $\mathrm{AA}$ & AA & 62.10 \\
\hline $16.81-16$ & $\mathrm{AA}$ & AA & 64.18 \\
\hline $16.59-64$ & $\mathrm{AA}$ & $\mathrm{AA}$ & 65.10 \\
\hline $16.74-5$ & $\mathrm{AA}$ & AA & 65.10 \\
\hline $16.25-38$ & $\mathrm{AA}$ & AA & 65.80 \\
\hline $16.69-133$ & $\mathrm{AA}$ & $\mathrm{AA}$ & 67.30 \\
\hline $16.41-24$ & $\mathrm{AA}$ & AA & 67.47 \\
\hline $16.18-45$ & $\mathrm{AA}$ & $\mathrm{AA}$ & 70.00 \\
\hline 'Camarosa' & $\mathrm{AA}$ & AA & 71.43 \\
\hline $16.28-29$ & $\mathrm{AA}$ & AA & 72.63 \\
\hline $16.13-64$ & $\mathrm{AB}$ & $\mathrm{AB}$ & 9.53 \\
\hline $16.57-72$ & $\mathrm{AB}$ & $\mathrm{AB}$ & 12.50 \\
\hline $12.70-55$ & $\mathrm{AB}$ & $\mathrm{AB}$ & 13.63 \\
\hline $16.38-14$ & $\mathrm{AB}$ & $\mathrm{AB}$ & 14.68 \\
\hline $16.9-72$ & $\mathrm{AB}$ & $\mathrm{AB}$ & 14.80 \\
\hline $16.25-11$ & $\mathrm{AB}$ & $\mathrm{AB}$ & 14.98 \\
\hline $16.10-5$ & $\mathrm{AB}$ & $\mathrm{AB}$ & 15.03 \\
\hline $16.24-5$ & $\mathrm{AB}$ & $\mathrm{AB}$ & 15.07 \\
\hline $16.28-33$ & $\mathrm{AB}$ & $\mathrm{AB}$ & 15.43 \\
\hline $16.73-76$ & $\mathrm{AB}$ & $\mathrm{AB}$ & 15.98 \\
\hline $16.76-62$ & $\mathrm{AB}$ & $\mathrm{AB}$ & 16.25 \\
\hline $16.44-32$ & $\mathrm{AB}$ & $\mathrm{AB}$ & 16.35 \\
\hline $16.54-26$ & $\mathrm{AB}$ & $\mathrm{AB}$ & 16.68 \\
\hline $16.54-8$ & $\mathrm{AB}$ & $\mathrm{AB}$ & 16.68 \\
\hline $16.54-9$ & $\mathrm{AB}$ & $\mathrm{AB}$ & 16.70 \\
\hline $16.13-182$ & $\mathrm{AB}$ & $\mathrm{AB}$ & 17.03 \\
\hline $16.52-25$ & $\mathrm{AB}$ & $\mathrm{AB}$ & 17.03 \\
\hline $16.5-19$ & $\mathrm{AB}$ & $\mathrm{AB}$ & 17.53 \\
\hline
\end{tabular}

(Continued on next page) 


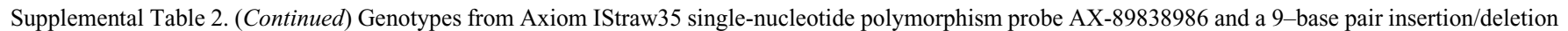
(InDel) assayed via high-resolution melting, and 2016-17 anthracnose fruit rot (AFR) incidence mean for four strawberry cultivars and 186 selections. AFR Incidence Mean (\%) was previously obtained from Salinas et al. (2019).

\begin{tabular}{|c|c|c|c|}
\hline Individual & AX-89838986 & InDel & AFR incidence mean (\%) \\
\hline $16.18-52$ & $\mathrm{AB}$ & $\mathrm{AB}$ & 17.70 \\
\hline $16.24-82$ & $\mathrm{AB}$ & $\mathrm{AB}$ & 17.70 \\
\hline $16.56-15$ & $\mathrm{AB}$ & $\mathrm{AB}$ & 17.90 \\
\hline $16.38-63$ & $\mathrm{AB}$ & $\mathrm{AB}$ & 18.03 \\
\hline $16.81-86$ & $\mathrm{AB}$ & $\mathrm{AB}$ & 18.28 \\
\hline $16.5-86$ & $\mathrm{AB}$ & $\mathrm{AB}$ & 18.43 \\
\hline $16.50-26$ & $\mathrm{AB}$ & $\mathrm{AB}$ & 18.60 \\
\hline $16.57-117$ & $\mathrm{AB}$ & $\mathrm{AB}$ & 18.60 \\
\hline FL_10-121 & $\mathrm{AB}$ & $\mathrm{AB}$ & 18.70 \\
\hline $16.13-45$ & $\mathrm{AB}$ & $\mathrm{AB}$ & 19.00 \\
\hline $16.26-15$ & $\mathrm{AB}$ & $\mathrm{AB}$ & 19.23 \\
\hline $16.76-81$ & $\mathrm{AB}$ & $\mathrm{AB}$ & 19.27 \\
\hline $16.50-23$ & $\mathrm{AB}$ & $\mathrm{AB}$ & 19.30 \\
\hline $16.77-18$ & $\mathrm{AB}$ & $\mathrm{AB}$ & 19.33 \\
\hline $16.28-44$ & $\mathrm{AB}$ & $\mathrm{AB}$ & 19.40 \\
\hline $16.18-137$ & $\mathrm{AB}$ & $\mathrm{AB}$ & 19.45 \\
\hline $16.81-136$ & $\mathrm{AB}$ & $\mathrm{AB}$ & 19.60 \\
\hline $16.74-27$ & $\mathrm{AB}$ & $\mathrm{AB}$ & 19.73 \\
\hline $16.73-77$ & $\mathrm{AB}$ & $\mathrm{AB}$ & 19.75 \\
\hline 16.24-19 & $\mathrm{AB}$ & $\mathrm{AB}$ & 20.30 \\
\hline $16.50-17$ & $\mathrm{AB}$ & $\mathrm{AB}$ & 20.38 \\
\hline $16.25-72$ & $\mathrm{AB}$ & $\mathrm{AB}$ & 20.73 \\
\hline $16.69-123$ & $\mathrm{AB}$ & $\mathrm{AB}$ & 21.35 \\
\hline $16.27-55$ & $\mathrm{AB}$ & $\mathrm{AB}$ & 21.63 \\
\hline $16.27-22$ & $\mathrm{AB}$ & $\mathrm{AB}$ & 21.68 \\
\hline $16.50-22$ & $\mathrm{AB}$ & $\mathrm{AB}$ & 21.88 \\
\hline $16.57-82$ & $\mathrm{AB}$ & $\mathrm{AB}$ & 21.90 \\
\hline $16.81-85$ & $\mathrm{AB}$ & $\mathrm{AB}$ & 22.05 \\
\hline $16.50-2$ & $\mathrm{AB}$ & $\mathrm{AB}$ & 22.15 \\
\hline $11.83-20$ & $\mathrm{AB}$ & $\mathrm{AB}$ & 22.34 \\
\hline $16.69-103$ & $\mathrm{AB}$ & $\mathrm{AB}$ & 22.58 \\
\hline $16.18-91$ & $\mathrm{AB}$ & $\mathrm{AB}$ & 22.63 \\
\hline $16.36-6$ & $\mathrm{AB}$ & $\mathrm{AB}$ & 22.67 \\
\hline $16.54-90$ & $\mathrm{AB}$ & $\mathrm{AB}$ & 22.70 \\
\hline $16.13-162$ & $\mathrm{AB}$ & $\mathrm{AB}$ & 23.00 \\
\hline 'Florida127' & $\mathrm{AB}$ & $\mathrm{AB}$ & 23.05 \\
\hline $16.17-38$ & $\mathrm{AB}$ & $\mathrm{AB}$ & 23.38 \\
\hline $16.18-36$ & $\mathrm{AB}$ & $\mathrm{AB}$ & 23.48 \\
\hline $16.36-18$ & $\mathrm{AB}$ & $\mathrm{AB}$ & 23.68 \\
\hline 16.81-109 & $\mathrm{AB}$ & $\mathrm{AB}$ & 23.73 \\
\hline $16.17-152$ & $\mathrm{AB}$ & $\mathrm{AB}$ & 23.80 \\
\hline $16.36-16$ & $\mathrm{AB}$ & $\mathrm{AB}$ & 23.93 \\
\hline $16.77-19$ & $\mathrm{AB}$ & $\mathrm{AB}$ & 23.93 \\
\hline $16.27-57$ & $\mathrm{AB}$ & $\mathrm{AB}$ & 23.97 \\
\hline $16.41-16$ & $\mathrm{AB}$ & $\mathrm{AB}$ & 23.98 \\
\hline $16.54-2$ & $\mathrm{AB}$ & $\mathrm{AB}$ & 24.03 \\
\hline $13.27-142$ & $\mathrm{AB}$ & $\mathrm{AB}$ & 24.10 \\
\hline $16.36-78$ & $\mathrm{AB}$ & $\mathrm{AB}$ & 24.13 \\
\hline $16.24-7$ & $\mathrm{AB}$ & $\mathrm{AB}$ & 24.17 \\
\hline $16.57-110$ & $\mathrm{AB}$ & $\mathrm{AB}$ & 24.28 \\
\hline $16.50-38$ & $\mathrm{AB}$ & $\mathrm{AB}$ & 24.48 \\
\hline $16.5-20$ & $\mathrm{AB}$ & $\mathrm{AB}$ & 24.53 \\
\hline $16.69-128$ & $\mathrm{AB}$ & $\mathrm{AB}$ & 24.68 \\
\hline $16.74-34$ & $\mathrm{AB}$ & $\mathrm{AB}$ & 24.68 \\
\hline $16.73-32$ & $\mathrm{AB}$ & $\mathrm{AB}$ & 25.05 \\
\hline $16.56-95$ & $\mathrm{AB}$ & $\mathrm{AB}$ & 25.15 \\
\hline $16.36-13$ & $\mathrm{AB}$ & $\mathrm{AB}$ & 25.25 \\
\hline $16.38-2$ & $\mathrm{AB}$ & $\mathrm{AB}$ & 25.27 \\
\hline 'Florida Elyana' & $\mathrm{AB}$ & $\mathrm{AB}$ & 26.13 \\
\hline 'Florida Brilliance' & $\mathrm{AB}$ & $\mathrm{AB}$ & 31.51 \\
\hline $16.13-48$ & $\mathrm{AB}$ & $\mathrm{AB}$ & 51.08 \\
\hline $16.10-46$ & $\mathrm{AB}$ & $\mathrm{AB}$ & 51.28 \\
\hline $16.10-11$ & $\mathrm{AB}$ & $\mathrm{AB}$ & 51.45 \\
\hline $16.13-34$ & $\mathrm{AB}$ & $\mathrm{AB}$ & 53.80 \\
\hline $16.25-53$ & $\mathrm{AB}$ & $\mathrm{AB}$ & 60.45 \\
\hline $16.10-7$ & $\mathrm{AB}$ & $\mathrm{AB}$ & 65.37 \\
\hline $16.5-32$ & $\mathrm{BB}$ & $\mathrm{BB}$ & 6.43 \\
\hline $16.60-145$ & $\mathrm{BB}$ & $\mathrm{BB}$ & 8.40 \\
\hline $16.38-45$ & BB & $\mathrm{BB}$ & 10.00 \\
\hline $16.28-23$ & $\mathrm{BB}$ & $\mathrm{BB}$ & 10.78 \\
\hline $16.10-2$ & BB & $\mathrm{BB}$ & 11.50 \\
\hline $16.17-118$ & $\mathrm{BB}$ & $\mathrm{BB}$ & 11.68 \\
\hline
\end{tabular}

(Continued on next page) 
Supplemental Table 2. (Continued) Genotypes from Axiom IStraw35 single-nucleotide polymorphism probe AX-89838986 and a 9-base pair insertion/deletion (InDel) assayed via high-resolution melting, and 2016-17 anthracnose fruit rot (AFR) incidence mean for four strawberry cultivars and 186 selections. AFR Incidence Mean (\%) was previously obtained from Salinas et al. (2019).

\begin{tabular}{|c|c|c|c|}
\hline$\overline{\text { Individual }}$ & AX-89838986 & InDel & AFR incidence mean (\%) \\
\hline $16.73-89$ & $\overline{\mathrm{BB}}$ & $\mathrm{BB}$ & 12.30 \\
\hline $16.40-92$ & $\mathrm{BB}$ & $\mathrm{BB}$ & 12.63 \\
\hline $16.26-16$ & $\mathrm{BB}$ & $\mathrm{BB}$ & 13.40 \\
\hline $16.50-39$ & $\mathrm{BB}$ & $\mathrm{BB}$ & 13.50 \\
\hline $16.49-10$ & $\mathrm{BB}$ & $\mathrm{BB}$ & 14.00 \\
\hline $16.41-14$ & $\mathrm{BB}$ & $\mathrm{BB}$ & 14.05 \\
\hline $16.38-83$ & $\mathrm{BB}$ & $\mathrm{BB}$ & 14.60 \\
\hline $16.38-79$ & $\mathrm{BB}$ & $\mathrm{BB}$ & 14.63 \\
\hline $16.49-72$ & $\mathrm{BB}$ & $\mathrm{BB}$ & 14.65 \\
\hline $16.28-36$ & $\mathrm{BB}$ & BB & 15.20 \\
\hline $16.27-21$ & $\mathrm{BB}$ & $\mathrm{BB}$ & 16.07 \\
\hline $16.24-4$ & $\mathrm{BB}$ & $\mathrm{BB}$ & 16.08 \\
\hline $16.10-51$ & $\mathrm{BB}$ & $\mathrm{BB}$ & 16.30 \\
\hline $16.73-114$ & $\mathrm{BB}$ & $\mathrm{BB}$ & 16.53 \\
\hline $16.5-41$ & $\mathrm{BB}$ & $\mathrm{BB}$ & 16.63 \\
\hline $16.40-44$ & $\mathrm{BB}$ & $\mathrm{BB}$ & 17.30 \\
\hline $16.73-88$ & $\mathrm{BB}$ & BB & 17.35 \\
\hline $13.22-336$ & $\mathrm{BB}$ & BB & 17.43 \\
\hline $16.27-35$ & $\mathrm{BB}$ & BB & 18.10 \\
\hline $16.49-32$ & $\mathrm{BB}$ & BB & 18.50 \\
\hline $16.10-48$ & $\mathrm{BB}$ & $\mathrm{BB}$ & 18.63 \\
\hline $16.5-81$ & $\mathrm{BB}$ & BB & 18.68 \\
\hline $16.44-54$ & $\mathrm{BB}$ & BB & 18.88 \\
\hline $16.26-19$ & $\mathrm{BB}$ & $\mathrm{BB}$ & 19.08 \\
\hline $16.10-9$ & $\mathrm{BB}$ & $\mathrm{BB}$ & 19.18 \\
\hline $16.19-45$ & $\mathrm{BB}$ & BB & 19.18 \\
\hline $16.17-58$ & $\mathrm{BB}$ & BB & 19.35 \\
\hline $16.27-30$ & $\mathrm{BB}$ & BB & 19.55 \\
\hline $16.10-45$ & $\mathrm{BB}$ & BB & 19.68 \\
\hline $16.40-16$ & $\mathrm{BB}$ & $\mathrm{BB}$ & 19.98 \\
\hline $11.31-54$ & $\mathrm{BB}$ & $\mathrm{BB}$ & 20.18 \\
\hline $16.19-74$ & $\mathrm{BB}$ & BB & 20.23 \\
\hline $16.49-62$ & $\mathrm{BB}$ & BB & 20.33 \\
\hline $16.49-67$ & $\mathrm{BB}$ & $\mathrm{BB}$ & 21.08 \\
\hline $16.5-44$ & $\mathrm{BB}$ & BB & 21.10 \\
\hline $12.55-220$ & $\mathrm{BB}$ & BB & 21.25 \\
\hline $16.24-91$ & $\mathrm{BB}$ & BB & 21.58 \\
\hline $16.17-32$ & $\mathrm{BB}$ & BB & 21.75 \\
\hline $16.17-133$ & $\mathrm{BB}$ & BB & 21.80 \\
\hline $16.52-73$ & $\mathrm{BB}$ & BB & 23.70 \\
\hline $16.49-73$ & $\mathrm{BB}$ & $\mathrm{BB}$ & 24.13 \\
\hline $16.5-64$ & $\mathrm{BB}$ & BB & 24.17 \\
\hline $16.19-80$ & $\mathrm{BB}$ & $\mathrm{BB}$ & 24.35 \\
\hline $16.49-54$ & $\mathrm{BB}$ & BB & 24.95 \\
\hline $16.17-148$ & $\mathrm{BB}$ & $\mathrm{BB}$ & 25.07 \\
\hline $16.26-17$ & $\mathrm{BB}$ & $\mathrm{BB}$ & 25.18 \\
\hline
\end{tabular}


Supplemental Table 3. Genotypes from Axiom IStraw35 SNP probe AX-89838986 and a 9-base pair insertion/deletion (InDel) assayed via high-resolution melting, and 2017-18 leaf area growth (LAG) difference means (\%) after root inoculation of 10 strawberry cultivars and one selection.

\begin{tabular}{lccr}
\hline Individual & AX-89838986 & InDel & LAG difference means (\%) \\
'Strawberry Festival' & AA & AA & 52.78 \\
'Monterey' & AA & AA & 64.40 \\
$14.34-33$ & AA & AA & 72.11 \\
'Fronteras' & AA & AA & 72.36 \\
'Treasure' & AA & AA & 95.10 \\
'Florida Beauty' & AA & AA & 96.10 \\
'Florida127' & AB & AB & 36.36 \\
'Florida Brilliance' & AB & AB & 41.89 \\
'Florida Elyana' & AB & AB & 61.67 \\
'Sweet Charlie' & AB & AB & 68.70 \\
WinterStar' & AB & AB & 75.86 \\
\hline
\end{tabular}


Supplemental Table 4. Genotypes from Axiom IStraw35 SNP probe AX-89838986 and a 9-base pair insertion/deletion (InDel) assayed via high-resolution melting, and 2018-19 leaf area growth (LAG) difference means (\%) after root inoculation of 11 strawberry cultivars and 49 selections. Genotypes differing between the two markers are in bold.

\begin{tabular}{|c|c|c|c|}
\hline Individual & AX-89838986 & InDel & LAG difference means ( $(\%)$ \\
\hline $13.55-195$ & $\mathrm{AA}$ & $\mathrm{AA}$ & 70.07 \\
\hline $17.45-83$ & AA & AA & 71.78 \\
\hline $14.34-33$ & AA & AA & 72.08 \\
\hline $11.108-5$ & AA & AA & 72.91 \\
\hline $16.2-161$ & AA & AA & 73.47 \\
\hline $15.42-146$ & AA & AA & 73.99 \\
\hline 'Strawberry Festival' & AA & AA & 76.76 \\
\hline $17.45-74$ & $\mathrm{AA}$ & $\mathrm{AA}$ & 80.76 \\
\hline $14.43-47$ & AA & AA & 83.10 \\
\hline $16.58-138$ & AA & AA & 83.84 \\
\hline $17.15-187$ & AA & AA & 86.06 \\
\hline $17.15-221$ & $\mathrm{AA}$ & AA & 88.03 \\
\hline 'Treasure' & AA & AA & 88.23 \\
\hline $15.9-137$ & AA & AA & 92.04 \\
\hline $15.34-82$ & AA & AA & 94.42 \\
\hline 'Florida Beauty' & $\mathrm{AA}$ & AA & 95.67 \\
\hline 'Monterey' & $\mathrm{AA}$ & AA & 97.10 \\
\hline 'Fronteras' & AA & AA & 97.16 \\
\hline $17.57-12$ & $\mathrm{AA}$ & AA & 99.23 \\
\hline $16.84-194$ & $\mathrm{AB}$ & $\mathrm{AB}$ & 21.79 \\
\hline $16.5-89$ & $\mathrm{AB}$ & $\mathrm{AB}$ & 43.79 \\
\hline $15.29-47$ & $\mathrm{AB}$ & $\mathrm{AB}$ & 47.45 \\
\hline 'Florida127' & $\mathrm{AB}$ & $\mathrm{AB}$ & 55.58 \\
\hline $14.83-36$ & $\mathrm{AB}$ & $\mathrm{AB}$ & 59.30 \\
\hline $16.41-166$ & $\mathrm{AB}$ & $\mathrm{AB}$ & 63.21 \\
\hline 'Florida Brilliance' & $\mathrm{AB}$ & $\mathrm{AB}$ & 67.44 \\
\hline $14.55-203$ & $\mathrm{AB}$ & $\mathrm{AB}$ & 67.52 \\
\hline 'Winter Star' & $\mathrm{AB}$ & $\mathrm{AB}$ & 70.55 \\
\hline $12.70-55$ & $\mathrm{AB}$ & $\mathrm{AB}$ & 74.20 \\
\hline 17.34-80 & $\mathbf{A B}$ & $\mathbf{A A}$ & 75.28 \\
\hline $15.46-86$ & $\mathrm{AB}$ & $\mathrm{AB}$ & 75.37 \\
\hline $17.21-86$ & $\mathrm{AB}$ & $\mathrm{AB}$ & 75.53 \\
\hline $15.76-129$ & $\mathrm{AB}$ & $\mathrm{AB}$ & 75.86 \\
\hline $13.27-142$ & $\mathrm{AB}$ & $\mathrm{AB}$ & 79.56 \\
\hline $12.5-130$ & $\mathrm{AB}$ & $\mathrm{AB}$ & 80.03 \\
\hline 'Sweet Charlie' & $\mathrm{AB}$ & $\mathrm{AB}$ & 80.08 \\
\hline $16.33-8$ & $\mathrm{AB}$ & $\mathrm{AB}$ & 82.28 \\
\hline $16.30-35$ & $\mathrm{AB}$ & $\mathrm{AB}$ & 82.71 \\
\hline $16.81-23$ & $\mathrm{AB}$ & $\mathrm{AB}$ & 84.28 \\
\hline $17.30-57$ & $\mathrm{AB}$ & $\mathrm{AB}$ & 84.72 \\
\hline 'Florida Elyana' & $\mathrm{AB}$ & $\mathrm{AB}$ & 89.04 \\
\hline 17.1-49 & BB & $\mathbf{A B}$ & 16.66 \\
\hline $17.1-6$ & $\mathrm{BB}$ & $\mathrm{BB}$ & 29.26 \\
\hline FL_09-57 & BB & BB & 29.51 \\
\hline $12 . \overline{7} 4-39$ & BB & $\mathrm{BB}$ & 41.00 \\
\hline 'Winter Dawn' & $\mathrm{BB}$ & $\mathrm{BB}$ & 44.71 \\
\hline $13.22-200$ & $\mathrm{BB}$ & BB & 47.44 \\
\hline $17.10-184$ & BB & BB & 49.90 \\
\hline $16.53-72$ & $\mathrm{BB}$ & $\mathrm{BB}$ & 51.52 \\
\hline $17.1-34$ & BB & BB & 55.26 \\
\hline $14.60-54$ & BB & $\mathrm{BB}$ & 57.76 \\
\hline $12.55-220$ & BB & BB & 64.69 \\
\hline $13.22-336$ & BB & BB & 70.31 \\
\hline $17.1-71$ & BB & $\mathrm{BB}$ & 71.69 \\
\hline $16.49-90$ & $\mathrm{BB}$ & $\mathrm{BB}$ & 72.10 \\
\hline $17.10-155$ & BB & BB & 73.10 \\
\hline $17.1-13$ & $\mathrm{BB}$ & $\mathrm{BB}$ & 74.97 \\
\hline $15.21-98$ & $\mathrm{BB}$ & $\mathrm{BB}$ & 81.11 \\
\hline $15.74-11$ & BB & $\mathrm{BB}$ & 85.09 \\
\hline $16.65-32$ & BB & BB & 99.98 \\
\hline
\end{tabular}

